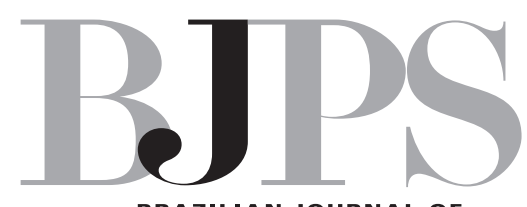

Brazilian Journal of

\title{
70 years of development of Pharmaceutical Sciences. A lot to celebrate!
}

When announcing the celebrations of our 70 years of publication, we immediately questioned ourselves about the motive of such celebrations. After all, what and why were we celebrating?! Was it just for protocol? Political reasons? To attend our own interests? NO! We were celebrating the evolution!

Not only the simple evolution of our Journal as such, or the evolution of its respective trajectory; but mainly, what it has represented, and currently represents, for teaching and research activities, for technological development and, ultimately, for the Pharmaceutical Sciences in our country.

When looking for information respecting the beginning of our publication, we found in the words from Prof. Lineu Prestes, at that time director of the Faculty of Pharmacy and Odontology of the University of São Paulo, the enthusiasm that marked an epoch of great advancement: “...the pharmaceutical teaching reaches its aspiration to possess a laboratory of industrial assays, where Brazilian raw materials will be studied and utilized, enriching our economy; laboratories such as the one of Botany and Pharmacognosy had their facilities very improved, enriching the teaching material with expensive apparatuses that will develop, from now on, studies related to our rich and exuberating medicinal flora; the laboratory of Galenic Pharmacy, which constitutes the better national teaching organization of this important discipline, is ready to develop researches and works that will fatefully result in scientific and technical amelioration of Brazilian pharmaceutical specialties; the laboratory of Chemical Pharmacy, which is well installed now, will induce in the students the investigative spirit and provide them with the necessary resources for the study of drugs under this pharmacologic aspect..., the laboratories of Analytical, Toxicological, and Bromatological Chemistry have suffered a deep renovation and are apt to form scientists who will attend the social feature of great industries concerning to intoxications of professional origin, besides to shape men of science able to face the serious problem of modern chemical warfare; the Parasitology laboratory, which is currently provided with ample facilities, could concur for the solution of serious medical problems." (Prestes, 1939). It was under this perspective and with a spirit of great enthusiasm the previously called Faculty of Pharmacy and Odontology of the University of São Paulo started the publication of the ANAES that, according to its first Commission, "will be a sure revelation of the value and competence of our faculty" (v.39, 1939). In that period, thanks to the improvements implemented in the University administrations, it was already possible to figure out the notable improvement in the teaching level, and the Faculty raised itself to the position of better establishment 


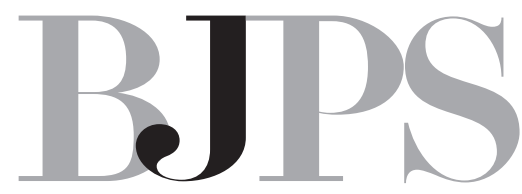

Brazilian Journal of

Pharmaceutical Sciences

of pharmaceutical and odontological teaching in Brazil, as exposed by Campos, in 2004. He emphasizes even that "scientific and technical researches were intensified in the several laboratories, as the regular publication of Anaes provided them with an adequate mean of divulgence". And during the subsequent administrative managements of Prof. Maciel de Castro, Prof. João de Sampaio Dória, Prof. Cyro Silva, and Prof. Paulo de Toledo Artigas, new promising facts could be seen "beside the significant outbreak of scientific researches attested by the number and level of 'Anais' editions” (Campos, 2004). In 1944-45, vol. 4, in Presentation Note from the Commission, it is stated the essentially scientific hallmark of the journal: "So, the 'Anais' present an evident trend to consummate its real objectives: to include only observational and experimental works, leaving that purely speculative to be published in magazines, yearbooks etc." (A Comissão, 1944-1945). From 1939 up to 1962, nineteen volumes of the Anais da Faculdade de Farmácia e Odontologia da Universidade de São Paulo were published; the last two volumes presenting the works of pharmaceutical area in the first issue, and those of odontological area in the second issue of the volume.

In 1962, with the separation of the Pharmacy and Odontology courses, and the consequent creation of two independent Faculties: the Faculty of Odontology and the Faculty of Pharmacy and Biochemistry, the 'Anais', following such change, was succeeded by the "Revista da Faculdade de Farmácia e Bioquímica da Universidade de São Paulo”, whose first volume was edited in 1963.

In that year, under the Direction of Prof. Henrique Tastaldi, and having as Vice-Director Prof. Tharcillo N. de Toledo, the Faculty of Pharmacy and Biochemistry moved itself to the university campus, place in which several disciplines continued to be offered. In the words of Pourchet-Campos, the 60s' decade was the decade of teaching reformulations, neither solely in Brazil, nor exclusively in the pharmaceutical field, but also in the university as a whole and in multiple countries. The regular graduate courses were defined and regulated, it was created the "Fundação para o Remédio Popular - FURP", the first "academic journeys" occurred as a result of students engagement in epidemiological and sanitary issues and curricular innovations took place. In this phase, from 1963 up to 1969, seven volumes were edited, comprising 182 papers, which represented a growth in the number of published works, showing that the scenario of the investigation developed in the Faculty was effectively promising. In that period, the endogenic character of the publication was still persisting, as only the works from the faculty were published. Right before the Faculties' separation, different cathedras were effectively considered by CAPES, at that time "Campanha de Aperfeiçoamento do Pessoal de Ensino Superior", and received trainees and/or fellowship holders developing studies and researches in their respective area of interest. From 1955 up to 1970, about one hundred of trainees and/or fellowship holders passed by the Faculty laboratories, pursuing to improve their knowledge, to serve as teachers at their original institutions (Pourchet-Campos, 1984). 


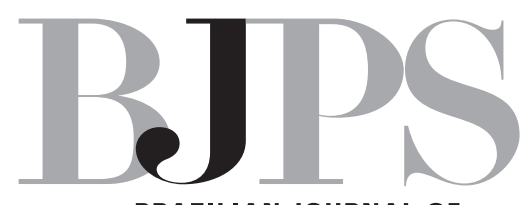

Brazilian Journal of

Pharmaceutical Sciences

On January $25^{\text {th }}, 1970$, it was developed the last Congregation Meeting of the Faculty of Pharmacy and Biochemistry, which after the University of São Paulo reformation and the implantation of its new statute, passed to be named Faculty of Pharmaceutical Sciences. Then, assume the direction of the "new" Faculty, as Director and Vice-Director, respectively, Prof. Durval Mazzei Nogueira and Prof. Robert Wasicky. Face to this change, the Publication passes to be named "Revista de Farmácia e Bioquímica da Universidade de São Paulo", with the explicative subtitle of "Órgão Oficial da Faculdade de Ciências Farmacêuticas" and, according to a note published at vol. 8, 1970, it "will embrace all the disciplines that concur for the formation of the 'Pharmacist-Biochemist'...". The new decade was being auspicious, the University campus was already presenting its own face; the Departments were better equipped and having their research works amplified, thanks to agreements or specific budgets addressed to graduate courses; the library was organized and offering a patrimony that enabled all bibliographic research ambitions necessary to the works of scientific investigation; and the Journal reflecting its age, presented in the volumes 8 to 34, corresponding to years 1970 to 1998,441 papers.

But the advancements continued, the "formerly therapeutic nihilism, characterized by empiricism in the utilization of therapeutic agents, no more existed; the therapeutic revolution was occurring, and was so named due to an extraordinary progress in Chemistry and Biology and the emergence of new drugs; the advancement of Pharmaceutical Sciences, with the assimilation of modern methods and techniques of scientific investigation, provided the possibility of drugs design and a true transformation in the art of formulating medicines; an amelioration occurred as in the technology of food and experimental nutrition areas, as in the diseases diagnosis" (Oga, 1998). At the same time, it is observed the Journal improvement; with special emphasis for the year of 1993, when it passed by a substantial change, incorporating an Editorial Body composed by experts in the Pharmaceutical and related areas, and the introduction of the Scientific Editor role, the first one being Prof. Andrejus Korolkovas. To him, the Journal and the Pharmaceutical Sciences all over the country should render their homage. With his typical enthusiasm and confidence, Prof. Korolkovas fought for the Journal when nationalism missing ideas gave much more credit to international publications. At that time, it was almost a common sense that a national publication could not subsist, considering so many difficulties that have to be faced, especially the lack of financial support for publishing. Facing all obstacles, Prof. Korolkovas took the responsibility for the Journal up to his last years of life, being replaced by Prof. Elizabeth Igne Ferreira, in 1996. In that period, as well, the Revista de Farmácia e Bioquímica da Universidade de São Paulo was not considered anymore as the official organ of the Faculty, but became more comprehensive, presenting papers from researchers of different country regions, besides foreign works. As exposed by the Scientific Editor, Prof. Elizabeth Igne Ferreira, "the research development in pharmaceutical areas experienced by the country, and the larger projection achieved by the Journal, were the incentive for the widening of its scope and range. We 


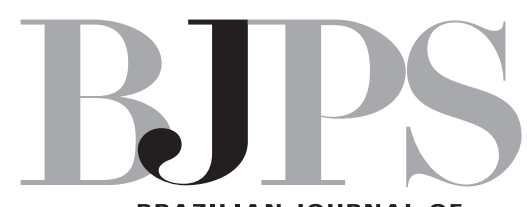

Brazilian Journal of

Pharmaceutical Sciences

surpassed the strict limits of Pharmacy and Biochemistry, to embrace the ample and multidisciplinary field of Pharmaceutical Sciences. This new phase starts with the conviction that it is imperative to reinforce all good quality national journals...", so, it was born the Revista Brasileira de Ciências Farmacêuticas/Brazilian Journal of Pharmaceutical Sciences (RBCF/BJPS).

The $R B C F / \mathrm{BJPS}$ has firmed itself in the national scenario as a reference in the area of Pharmaceutical Sciences, climbing the stairs for its internationalization; it was excellently classified by Qualis, National "A" and International "C"; indexed in important databases; and presented, also, a considerable impact index in the SciELO database, among the periodicals of Health Sciences area. It has developed a sustainable growth in the last years, as verifiable through the below presented Graphics I to III; there is an increase in the number of works submitted and published; the majority of papers are original works; and a visible breakage of the Journal's endogenic character has occurred along the years, as well. But, its quality improvement is also linked to its visibility and search for recognition by the scientific community.

At the same time, it is known that scientific publications should act as indicators of the researchers academic performance and, for this purpose, are essential the dissemination, the indexation, and the effective action through electronic means. The academy was requiring the publication international recognition, and it was known that the great challenge for higher visibility was the vernacular. Intensive debates and reflections marked the meetings of the Publication Committee. After all, as questioned by Meneghini and Parker, "Is there science beyond English?". As they have well underlined, the SciELO has helped to break the language barrier within scientific communication, but would be enough such initiatives, to avoid the "loss" of the science we intend to divulge?

And, with the intention to take all over the world the Pharmaceutical Sciences produced in Brazil and, even, to serve as a mean of divulgation of works from other countries, in the first fascicle of this volume, the Scientific Editor, Prof. Elizabeth, has presented to the academy the current Brazilian Journal of Pharmaceutical Sciences. Enthusiastically, with her force to determine new routes and guide the procedures, and having the support from the Publication Committee she has enabled us to climb one more stair in the history, having "our" Journal as a reflex of an Institution that has always searched, and searches, the continuous improvement and innovation of the Pharmaceutical Sciences.

Leila Rangel de Carvalho Aranha

Executive Editor 


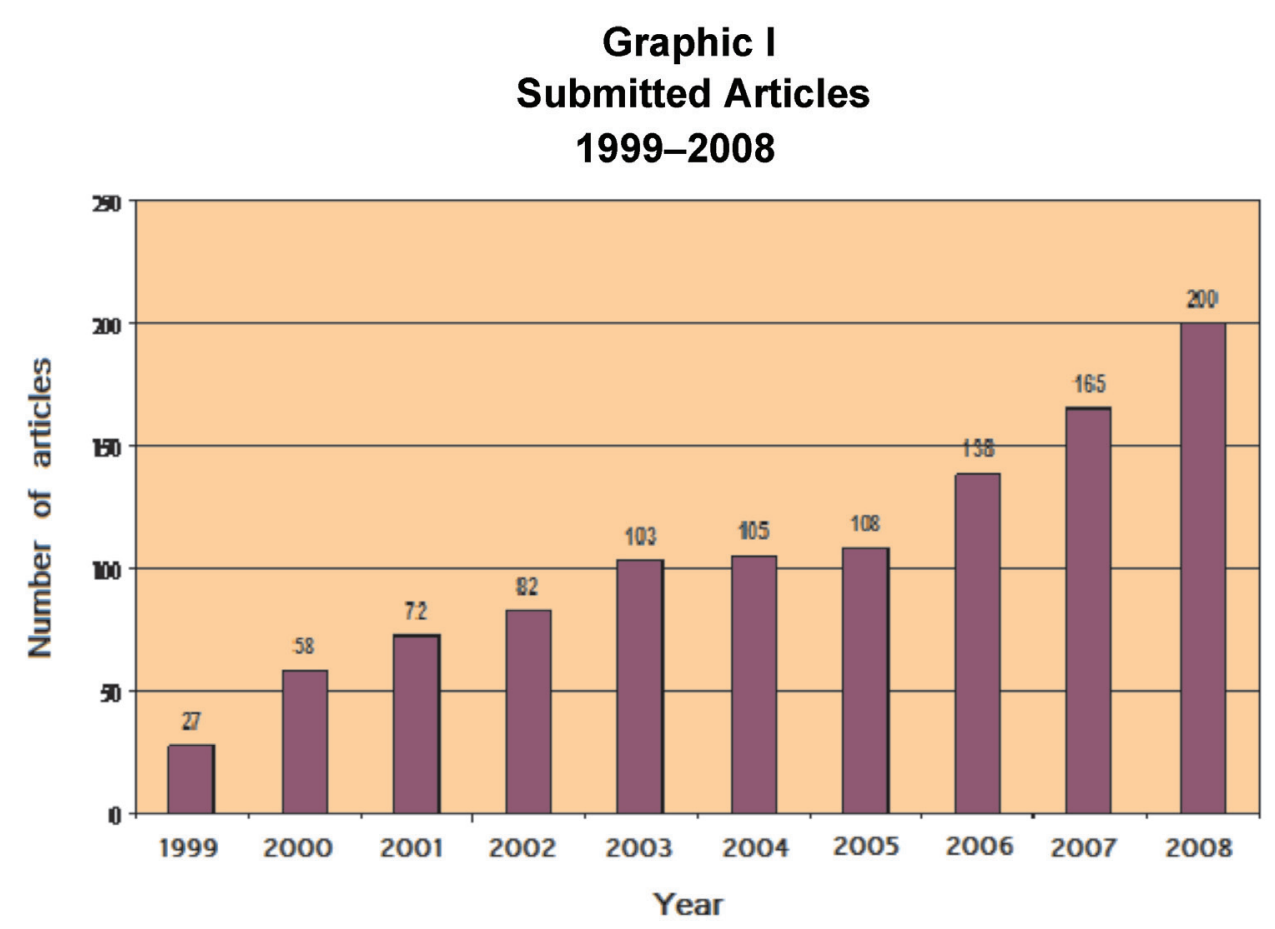

Graphic II

Published Articles/Type of document

1999-2008

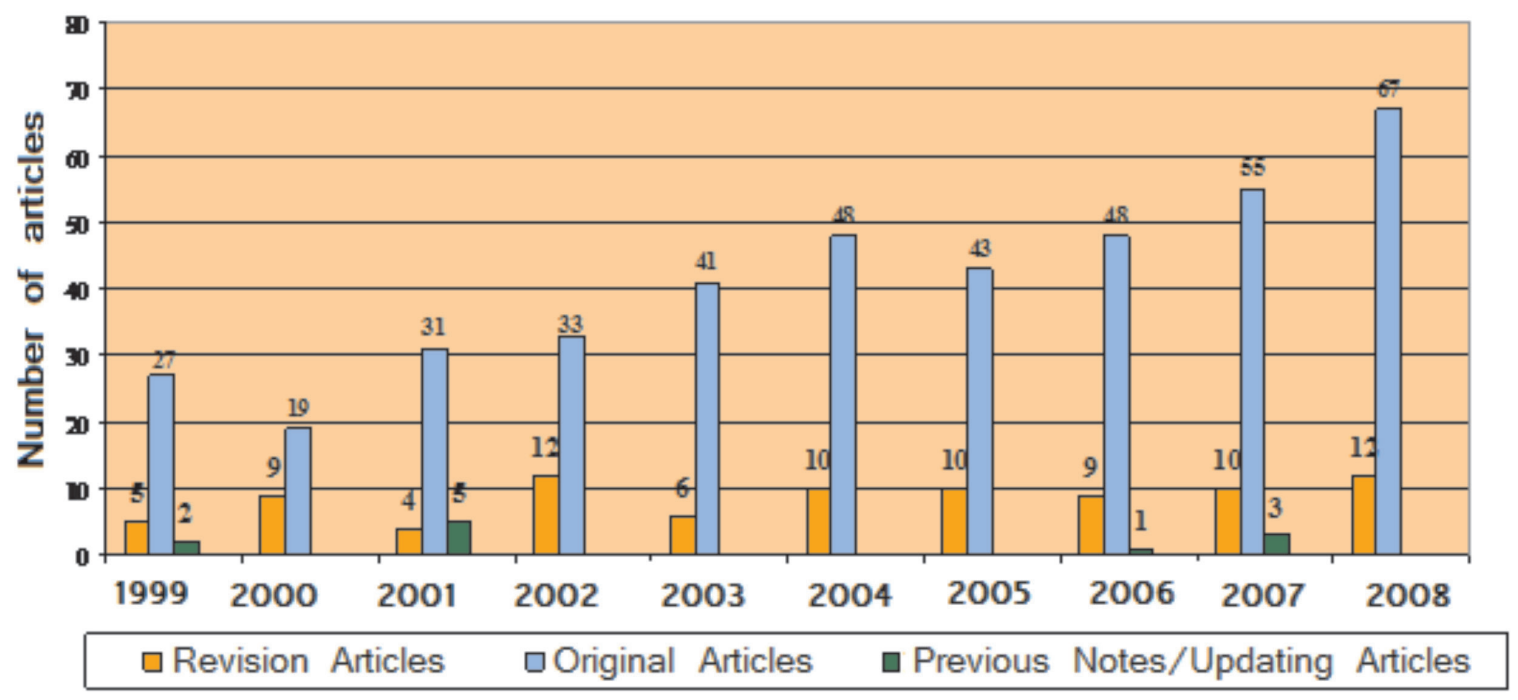




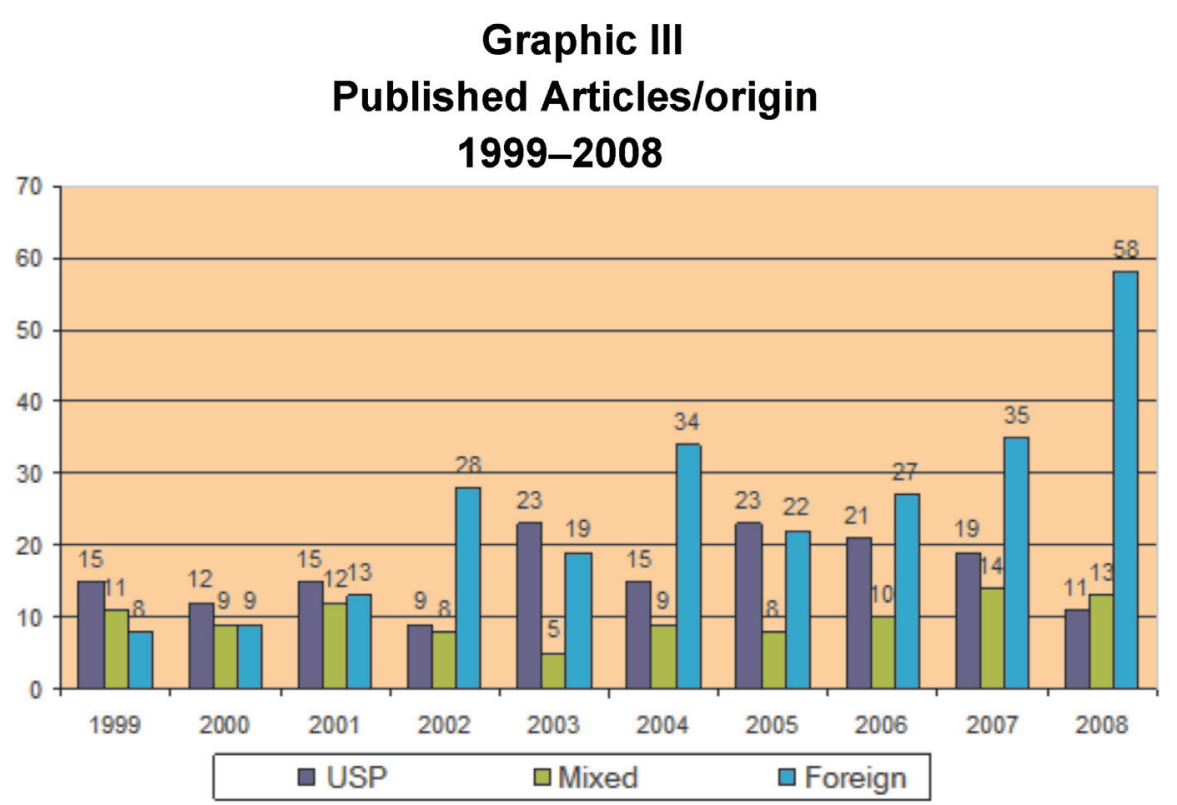

- Articles developed by Units of the University of São Paulo

- Articles developed by Units of the University of São Paulo in collaboration with others Institutions

- Articles developed by foreign na non-USP national Institutions

\section{REFERENCES}

CAMPOS, E. S. História da Universidade de São Paulo. 2.ed. São Paulo: EDUSP, 2004. 439-447p.

A COMISSÃO. Apresentação. An. Fac. Farm. Odontol. Univ. São Paulo, v.4, p.5, 1944-1945.

FERREIRA, E. I. Editorial. Rev. Bras. Ciênc. Farm., v.35, n.1, 1999. p.i.

MENEGHINI, R.; PACKER, A. L. Is there science beyond english? Embo Rep., v.8, n.2, p.112-116, 2007.

NOVA denominação da Revista. Nota explicativa. Rev. Farm. Bioquím. Univ. São Paulo, v.8, n.1, não paginado, 1970.

OGA, S. Apresentação - Universidade de São Paulo. Faculdade de Ciências Farmacêuticas. 100 anos. In: UNIVERSIDADE de São Paulo. Faculdade de Ciências Farmacêuticas. 100 anos. [São Paulo]: Mara Mazzini Editora, 1998. p.3.

POURCHET-CAMPOS, M. A. A vida da Faculdade de Ciências Farmacêuticas da Universidade de São Paulo - Notas históricas.

São Paulo: Ponto Cardeal Publicações, 1984. p. 68, p.74, p.80, p.89-90.

PRESTES, L. Of. 7647. dirigido ao DD. Interventor Federal no Estado de São Paulo, Dr. Adhemar Pereira de Barros. An. Fac. Farm. Odontol. Univ. São Paulo, v.1, p.1-2, 1939-1940.

UNIVERSIDADE de São Paulo. Faculdade de Ciências Farmacêuticas. 100 anos. [São Paulo]: Mara Mazzini Editora, 1998. 86p. 